\title{
Aso-oke (Hand Woven Textiles) of Southwestern Nigeria A Compact Examination of a Resilient Artifact
}

\author{
Olutayo, A. $\mathbf{O}^{1}$, Olayinka Akanle ${ }^{1, *}$, Fadina, O. $\mathrm{A}^{2}$ \\ ${ }^{1}$ Department of Sociology, Faculty of the Social Sciences, University of Ibadan, Nigeria \\ ${ }^{2}$ Environmental Studies and Sustainability Science, Lund University, Sweden
}

\begin{abstract}
Aso-oke is a peculiar artifact among the Yoruba people. Old and emerging dynamics within the Yoruba world systems and the nation at large are however reconfiguring the process, nature and existence of aso-oke. This paper undertakes a comprehensive, but compact, study of the factors responsible for the reconfigurations: namely, colonial influences, contemporary political and economic policies, demographic compositions and global influences on indigenous value construct. Through qualitative research design, this paper interrogates the vital issues surrounding aso-oke and concludes that though the artifact has witnessed some changes since the colonial era and is still changing under contemporary influences, it however subsists in its essence and the definition of the Yorubas and if properly annexed could be a viable tool in addressing some developmental challenges of the nation especially in terms of employment generation, industrial development, poverty eradication, elderly support, youth empowerment, and national identity protection in the global era.
\end{abstract}

Keywords Aso-oke, Southwestern Nigeria, Yoruba, Artifact

\section{Introduction}

It is indeed true that the only constant phenomenon in human history is change. More important however is the fact that changes never exist in a vacuum and usually constantly intermingle with that which predated it to produce a new category with definite element that will unmistakably suggest continuity. This is particularly the scenario when aso-oke is considered within appropriate and pragmatic frameworks. Different scholars have defined aso oke but it is taken to mean the Yoruba hand woven cloth on horizontal and vertical loom (Ojo, 2007) in this study. This definition is particularly found suitable as it sufficiently enmeshed the sociocultural and historical nature of the artifact with its technogical antecedents; very crucial elements in reference to existence especially for the purpose of this paper. Most of the previous studies on aso-oke of southwestern Nigeria suffer identical fate of excessively fragmented analysis and were tainted with gender sentiments, obsoleteness and epochal disconnect (Asakitipi, 2007; Renne, 1997; Poynor, 1980; Bray, 1968; Clarke, 1938; Murray, 1936).

The objective of the present study is to examine aso-oke in relation to its existence across periods. Embedded issues particularly relevant to the stated objective will be addressed in the course of this paper. A noticeable feature of the

* Corresponding author:

yakanle@yahoo.com (Olayinka Akanle)

Published online at http://journal.sapub.org/sociology

Copyright (C) 2011 Scientific \& Academic Publishing. All Rights Reserved
Yoruba people, particularly the economic organization, is that of specialization by compounds. While there is hardly any compound that is not without its quota of farmers; there are whole compounds to be found in large towns whose population is made up of people following the same trade. These are compounds of blacksmiths, of weavers, and of iron smelters amongst others. Although most people from Edo, Itsekiri, Kabba, Ilorin and Lagos speak Yoruba language, they are not considered in this study due to variations in historico-sociological events of the past and present.

Therefore, the analysis presented here is largely relevant to the contemporary Oyo, Osun, Ogun, Ondo and Ekiti states. All these are similar in their economic, political and social organization as they all trace their origin to Ile- Ife. Considering the vastness of the locus of relevance given above, and the fact that aso-oke textile industry now exists in pockets of places in the Nigerian southwest and the comatose in the overall Nigerian textile industry, the aso-oke as a major product of the weaving world thus requires a fresh examination in relation to basic information gathered from the areas of concentration of weavers in the southwestern Nigeria and this informs the study been conducted in Iseyin, Oyo state.

\section{Methods}

This research article study sourced data from individuals and groups who have been involved at different stages of production of aso-oke. The people interviewed included master weavers, farmers involved in the growing of raw 
materials across era, dyers, makers and fabricators of instruments (wooden and metal) used in the weaving process and those that have been involved in the sales and distribution. Respondents were selected through simple random sampling from the major weaving areas of Iseyin. The areas covered in the study were; Koso, Oke-Ola, Ijemba, Imale-falafia, Parakoyi, Isalu, Adabo, Agbaju, Oke-Oja, Odo-Oba and Idiose. A fundamental prerequisite for final inclusion of a respondent in the sample was 25-60 years of operational experience in the aso-oke industry. Due to the nature of study and socioeconomic background of the respondents, qualitative method was particularly favoured. As such, focus group discussion, key informant approach, in-depth interviews and observation were employed in the data collection process. Results and discussions of data gathered through the methods are presented below.

\section{Result and Discussions}

\subsection{Socio-cultural Import of Aso-oke}

Before colonial contact, weaving flourished in central and northern Yorubaland, especially in Owo, Ede, Ibadan, Ondo, Oyo, Ogbomoso, Ado- Ekiti and Iseyin towns. Thus, scholars of African textile technology (Afigbo and Okeke, 1985; and Ojo, 1966) agreed that prior to contact with 'western culture', the traditional Nigerian communities had developed indigenous technology ecological conditions of ingenuity. The raw materials for traditional weaving were largely obtained from the local environment. According to Afigbo and Okeke, (1985), archaeological findings confirm that indigenous technology in carding, spinning, dyeing and weaving had been a product of the peoples' effort to exploit their environment to advantage. They assert further, through efficient use of vertical and horizontal looms, communities such as Ilorin, Iseyin, Oyo, Okenne, Kano, Nupe,Kabba, Abeokuta, Ijebu-Ode and some other parts of Igboland were famous for the quality of their textile products, which was able to satisfy both domestic and foreign demands.

The indigenous evolution of the material inputs into aso-oke was ultimately resonated in intangible sociocultural essentials. In different communities of Yorubaland and at different times, aso-oke has taken on significance far beyond source functional clothing and serving as money but to a large extent as medicine, as a link between generations, families, and societies and as a key to the construction of group and individual identities (Clark, 1972; Lamb and Holmes, 1980; Olutayo, 1991). Yoruba cloths can be divided into three major categories of cloths for prestige, rites and ceremonies and cloths worn for daily use (Eicher, 1976; Lamb and Holmes, 1980). It is appropriate therefore to look into the context within which aso-oke operates.

Yoruba traditional setting maintains a reputable environment for the production of high quality and various textiles because the Yoruba culture has its scheme of values (Williams, 1998). Thus sanyan (Wild silk cloth) mostly referred to as baba aso ('king of cloths) in Yoruba tradition is naturally coloured beige Anaphe silk, though it may have a white central warp band in each strip (Lamb and Lamb, 1973). It is particularly associated with special robes for high rank chiefs and obas (kings). Etu, particularly the variety of sanyan called senior etu (etu nla) which comes in colours of high blue on a dark indigo background form part of many traditional ceremonies and functions and their weaving also implied status (Lamb and Lamb, 1973). Here sanyan and etu-nla described above were only woven within the premises of the king's palace and such weaving tasks were taken by old master weavers specially chosen for such tasks. This could perhaps surround the myth around the $o b a$ in traditional Yoruba setting as alase ekeji orisa (the all powerful only next to God) whose clothing must be handled not just by any weaver. Alaari which is the third of prestige cloths, originally made from a mixture of red camwood-dyed sanyan was also material for garments for chiefs in Yorubaland (Lamb and Lamb, 1973).

The Yorubas also categorized aso-oke used for rights and ceremonies. Those used for such occasions are called the aso alaro group of cloths (Lamb and Lamb, 1973).These are made from hand spun cotton which has been dyed with indigo, with, perhaps, warp patterns in varying blue shades and in the case of marriage some red warps as well ( Williams, 1998). Alaro cloths have neither holes nor inlays patterns; they are often beaten to give them glossy appearance (Lamb and Holmes, 1980). The red pattern in aso-alaro for marriage reflects on the colourful environment that surrounds marriage in Yorubaland. Thus, aso-oke plays an important role in marriage ceremonies that one should not be supprised to find a great variety of aso alaro amidst marriage ceremony. It is adequately important to note that the use of alaro cloth for marriage expresses celebration of affluence and the readiness to take the responsibilities of household and family.

Alaro cloth meant to be seen in the engagement ritual where the prospective groom or the family is expected to give the bride is punctuated with oparo cloths which are made from a selection of aso alaro pattern. Ideally, five patterns should figure in such combinations okin, alikinla, jija-maje, eleku and petuje. Funerals provide another occasion for the weaving of aso-alaro cloths. Here etu is also used. At all events of such, dark blue is the colour for all. The significance of colour preference is to demonstrate mourning as a symbol of respect for the dead. It can thus be inferred that respect for the dead is demonstrated in the Yoruba culture, in part, through weaving of special cloth. In the past, it is certain that aso-oke was an important to the Yoruba after death as it was in life to the extent that it played a major role in burial practices. Both nineteenth century and contemporary observers have recorded emphasis placed on aso-oke in Yoruba funerals. Thus, Bascom (1969), Lamb and Lamb, (1973), and Ellis, (1890) noted that apart from the use of alaro cloths, the custom of burying the deceased along with cloths of quality, as shrouds and as covers and 
accoutrements for the funeral bed and the actual burial; the practice depicts life after death. It is thus noteworthy that the import of aso-oke lies in deep Yoruba tradition and transcends economy and expediency thereby explaining their existence over time. It can further be inferred that the display of affluence, stratification, class and life after death amongst others are centred on aso-oke.

In the light of aso-oke worn for rites is the aso-olona (patterned aso-oke) which is won by lesser crowned rulers, chiefs, members of the Ogboni fraternity and priests mostly among the Ijebus and Egbas. The cloths with their richly decorated weft float patterns, symbolize "long life well lived" in sharp contrast to the plain white cloth. Thus the patterns and colours present the richness and diversity of an individual's experience in life including acquired knowledge of the spirit realm (Lamb and Holmes, 1980). The shag (saki) a variety of aso-oke woven on vertical looms is the principal feature of aso-olona. The shag which was expected to be worn outward for visibility is associated with power, prestige, and things that are good. Directly related to the spiritual or prestige references to this variety of aso-oke are the status and identity embeddedness.

A smaller type of the aso-olona ,Itagbe which is placed on the shoulder mostly by the chiefs in Ijebu and Egbalands functions as a constant reminder of the chief's subservient to the king. This is usually presented to the chief's as official chieftaincy attire after coral beads, caps and leather flywhisk had been presented to them. It is thus pertinent to note the relativity of aso-oke to the Yoruba culture in terms of authourity and identity. Because the itagbe is viewed as highly personalized symbol of one,s status and identity, it is frequently used to adorn the shrines of deities making aso-oke a significant totem it the matrix of traditional religion. Oja ( aso-oke specially woven to strap babies to mothers' back) is a popular brand of aso-oke among the Yorubas. Significantly, it is a major gift mothers-in-law give their daughters-in-law upon child's delivery as it is a major tool for nursing mothers who are expected to strap their babies to the back. Oja can be decorated with a wide variety of patterns and mostly have a center portion with a tufted or pile texture. The use of the tufted surface is certainly associated with ritual functions since it occurs in a special cloth woven for Ogboni (Eicher 1976).It may therefore be that these properties of tufted cloth are thought to be particularly suitable for the protection of babies.

The Yorubas are much given to participating in what might be called purely social clubs or meetings. This has been institutionalized that such gatherings are popularly known as a'remise (a kind of prayer/greeting at such gatherings meaning 'social functions are important and we will not die before we celebrate ours') .Aso-ebi are worn in such occasions. That is all present wear the same pattern on any on any particular occasion. Fadipe $(1970 ; 79)$ succinctly put it thus: "while the belle in western countries is somewhat mortified on finding that her select costume is duplicated in a crowd, the positive self feeling of the Yoruba is actually enhanced by having scores of her/his fellows dressed alike".
In fact not partaking in aso-ebi will most likely generate implicit hostility and this is usually avoided in a society where familial/informal relationships are highly valued even in the face of globalization with its attendant bahavioural implications as identification with kinsmen/women and collectivism can be seen as an innate character of the Yorubas.

It can thus be deduced that the type of aso-oke worn by a person in the Yoruba society not only speedily communicate the status of the person, it also denotes details about his culture particularly belief system and level of affluence. The sophistication of aso-oke making in the Yorubaland expresses its far-reaching effects not only beyond the social and spatio-economic space of southwestern Nigeria but also that the aso-oke varieties numbered above 150 distinct patterns (Lamb and Lamb, 1973).

\subsection{Implements Used in Weaving aso-oke}

Before colonial contacts, four types of loom existed in the Yoruba traditional weaving scene (Williams, 1998; Lamb and Lamb, 1976; Fadipe, 1970; Ojo, 1966; Dodwell, 1955). Among the people of Ado-Ekiti there existed the "bush loom" ( ofi oko) which was found to be ideal for light weaving. The twilling loom (ofi elejo) was agreed to have existed among the people of Ilorin which was said to have shared the same properties with that of Ado-Ekiti. The traditional strip loom was found among the people of Iseyin, Oyo, Saki, Ibadan, Ede, Abeokuta and other former Oyo province (Williams, 1998; Lamb and Lamb, 1976; Dodwell, 1955). The fourth type of loom that existed before colonial contact is the vertical loom, the construction and operation of which was said to be the same in all Yoruba communities. This type of loom is particularly suitable for weaving kijipa, itagbe, oja for example. Of particular interest is the fact that various looms in the Yoruba societies reflect environmental and cultural adaptation and the ability to develop a range of choices suitable for products' manufacturing in the industry.

The origin of the horizontal looms in West Africa is unknown but it may have come from Asia through Arabia (Gilroy, 1987). This view corroborates the submission of Dodwell (1955) that although the origin of weaving among the people of southwestern Nigeria is obscure it is thought to have been brought down along the trans caravan routes from the north. The chief feature of the Yoruba weaving is the narrowness of the cloth made on the loom which is usually in strips (Lamb and Lamb, 1973; Ojo, 1966). The traditional strip looms were constructed in a house manner (rectangular form) with an open end. It was built with mud and bamboo sticks (Fadipe, 1970). Apart from the loom, instruments used in (traditional) weaving industry includes; yarn pegs (Odaada), shuttle (oko), pattern divider (Ooya), thread sorting equipment ( Akata), Kokogun, Heddle (Omu), Agbonrin, weighted sledge ( Okuku) and Sanrin (long iron for warping process). Consensus exists among scholars that the instruments used in the (traditional) weaving and production process were made, mainly, from iron, wood, 
bamboo, raffia palm and calabash and these instruments were sourced from the local environment and were mostly fabricated by carpenters, blacksmith and forebears of the industry themselves -master weavers for instance-(Lamb and Lamb; Ojo, 1966; Dodwell, 1955; Wilkes, 1946).

The colonial policy made various attempts at the 'popularisation, perhaps 'modernising' the loom. In this connection, broad loom and the establishment of Textile Training Centres as part of the Textile Development Scheme (Renne, 1997) where training on broad loom was organized for the young ones and ex-service men but it was largely unsuccessful due to the lack of proper understanding of the associated sociocultural factors (Renne, 1997; Southern 1946). On the modifications that have come to the instruments of weaving, it was largely expressed by interviewees and participants at the FGD sessions that modifications mainly came to two implements; Ofi (loom) and the asa (reed). It was discovered in the course of investigation that the loom (weaving shed) as referred to by some respondents is now moveable unlike the fixed olden days built in form of a house. Also, it was found that in the old loom (traditional); the loom was made to accommodate an average of fifteen to thirty weavers while in the present horizontal loom (modern) weavers weave alone in the single movable loom.

Embedded in the material transformations is an associated alteration of the primordial communal mode of organization, processing and social relations in the aso-oke industry as individuals now work on the products without necessarily socializing with others. While this may enhance efficiency and optimal utilization of the production time, it may hold implications for the dynamics of oneness of the weavers especially as the production process is more often located within the family system. Particularly important from the foregoing is that familial and informal arrangements are known to be valuable in the sub-Sahara African setting with weak modern institutional arrangements. The social exclusion/extrication of the hand ginnery and spinning process made the concentration of weavers in a place less meaningful as weavers can now get thread for weaving wherever provided $\mathrm{s} / \mathrm{he}$ can afford it.

Data revealed that the changes in the loom make it easier to weave (i.e. physical comfort) than the old loom and it was generally gathered that the old the traditional strip loom no longer exist. Inquiries further revealed that change has come to the reed (asa) also. The change discovered in the reed is that there has been a modification in the string which yarn passes through during weaving. It was gathered that the reed in the traditional aso-oke industry was made from spine of the raffia palm tree which form the frame and the strings from the peel of bamboo stick while the modified one is made of wood plank and iron strings. It was evident in the course of the interviews that both the traditional and modern ones are still very much in use. The new reed is commonly in use because imported threads form the major bulk of thread used in the industry today. It was however gathered some customers prefer weave of traditional reed and that some clothes like sanyan cannot do well on the metal string reed. With the existence of the horizontal loom in the modern aso-oke industry, it was gathered from interviewees that the two reeds have been adapted into the horizontal (modern) loom. Hence, the loom can now weave cloth in the width of six to seven inches. The big, new reed (string made) can produce cloth wider in size and appear to be an adaptation of the broad loom introduced during the implementation of the Textile Development Scheme.

\subsection{Production Process of aso-oke}

In the traditional aso-oke industry of the Yorubas, the fundamental conviction of human society about the concept of work existed as all within the society and family partake in one degree or the other. As generally revealed in all the discussions and interviews, the end product of the production process-aso-oke- in the traditional form start with the farmers. The process begins with the planting of local cotton (owu tutu). It takes three months for the cotton to reach harvesting stage when it becomes fully white. Inquiries revealed that harvesting was mostly done by the women and children and sold to those who process the seed cotton into threads or processed by themselves. Important in this finding however is that this role is merely for division of labour and complementarity to enhance optimal productivity and does not suggest gender segregation, mainstreaming or outright subjugation as usually inferred by previous studies.

On the input material processing, investigation revealed that seed cotton was indigenously processed by hand. Getting the cotton prepared for weaving starts with the removal of seed cotton from the cotton seed. To remove the seeds, ginning usually involves placing cotton balls on a block of wood and rolling an iron rod over them. The pressure exerted on the moving cylindrical object pushes the seeds out of the cotton fibres. After the seeds are removed, the fibres must be aligned and this process is called ginning. The ginning process as gathered during the study was done indigenously through a bow type device called Okure. The device is used to fluff the cotton and straighten the fibres. This process produces the fluffy product which is ready to be spun into thread.

Spinning is mostly done traditionally, manually and very cumbersome. The spinner pulls and twists enough fibres to secure it to a spindle. Though it was gathered that spinning can take two major forms, but in this case the spindle is weighted by a clay whorl. The spinner sets the spindle in motion, draws fibres into a thread and winds them on the spindle. This instrument is called akowu. Inquiries into the origin of this instrument was gathered and it was revealed to have come from a tribe called Ibariba over a very long time ago and then modified to suit their purpose. Finally the thread gotten after spinning is wound into a skein called akate ekowu. When asked on how knowledge about cotton spinning was gained, interviews maintained such is gained through the family lineage as crafts are usually located 
within the family or compound (agbole) as it is customary among the Yorubas for every family to have a known handiwork/craftsmanship aside been farmers in most cases. In the case of a respondent, she opined that she learnt the skill when she was barely nine years old:

I got to know about thread making when I was young my grandmother taught us because she performed this task before her death and we (i.e. all young children) have to learn how thread is made because it our trade

On the dyeing process, investigations gathered reveals that the desired colour of the thread is obtained with particular leaves and plants depending on the colour. In the case of blue colour, dyeing starts with the collection of eluu leaves (Indigofera) which produces indigo blue. The leaves are fermented and dried in balls. The indigo cakes are then placed in a perforated pot (elekiti) which contains ash (as source of soluble alkaline). Water is poured into the top filter through the perforated holes into the bottom pots to obtain dye (omi aro). Preparation of dye in other colours however demands more specialized skills. The finesse with which the Yorubas produce dye has led so many researchers to the conclusion that indigo dying probably originated from the southwestern Nigeria. Apart from the findings that bark, roots and leaves are used in making dye stuff in the traditional aso-oke industry, it was further revealed that these plants formed the source of numerous dyes (colours) produced. As recounted by an interviewed dyer:

In those days (pre-colonial era) we used to produce red colour from leaves of guinea corn (ewe oka baba), back and roots of African rosewood (aga tree)... black from physic nut tree (opo owon) beige from bark of mango tree (epo igi mongoro).It was gathered that warps are made on the ground on pegs (serin) between which a weaver walks carrying from two to twenty threads at a time on a bobbin carrier called odaada. The length of the warp may sometimes be as long as five hundred metres. The warps are then entered into loom through the heddle (omu) through a meticulous process which may take a whole day. Strings from the heddle connect with the peddles (itese). One heddle with every alternative thread is pulled down. It is connected with the other heddle by a rising pulley (okeekee) hanging from the top of the roof. The other heddle is pulled up making a shed through which the shuttle (oko) can be thrown. The reed (asa) beats the weft of the yarn and used to ensure a firm neat woven fabric. The warp is attached to a weighted sledge (okuku) which is placed about sixty feet away from the loom and which is generally drawn up as the work proceeds with the aid of the cloth beam (agbonrin). This process which predates modern history still exists till date. On the other hand, the earlier process discussed from the aspect of cotton growing and spinning that existed in the traditional industry has been largely modified.

The dynamics of the modification being witnessed in the input material process (es) of the modern aso-oke is largely traceable to diffusion originally aided by colonialism as the primary agent of institutional change in the history of the nation as it altered fundamental liberty of cotton production and conversion process which serves as the root of the present widespread importation of yarn being used in the contemporary aso-oke industry. This alteration led to a massive shift from the production of cotton to the production of other cash crops such as Cocoa particularly favoured by the colonial development policies. According to Olutayo and Omobowale (2007), "Cocoa in particular became so entrenched in the socio-economic structure of south-western Nigeria became a predominant producer and was referred to as Nigeria's cocoa belt". Hence changes in the tastes and styles of current users to cope with the dictate of contemporary socioeconomic dictates to remain trendy even in traditional attires, especially among the youths who are the major trend setters also necessitated the modification of the end products. This summation was sustained by a respondent (a user and industry observer) when she opined that:

Aso-oke is still very much in use. The fact is that it is being modified to meet the present expectations of trend. I think this is fine and the modification is mainly in terms of adding silk to the raw materials to make it lighter and finer. However, some people even still prefer the original (traditional) type because they last longer and they are made of original cotton. Also, when you wear the original (traditional) type with to match (good colour combinations) people fall in love with it and they give you compliments that this your cloth is fine o o.

\subsection{Raw Materials Used in aso-oke Industry}

Investigation into the raw materials used in the modern aso-oke industry as against the traditional brought out appreciable difference. As expressed by the summation of the generality of the interviewees and participants in the FGDs:

The input materials (yarn, dye) are no more sourced locally

It was generally gathered that the allied industries of the aso-oke weaving process which are important auxiliary crafts to weaving in Yorubaland has been atrophied. Based on this atrophy, it is inferred that cotton/yarn used in the industry now are not locally sourced. The view of an interviewee (master weaver) is insightful in this regard:

Our forefathers used to grow cotton they used in weaving aso-oke on farms around, and it was a very common thing to find cotton plants even in homesteads farms because it was largely useful for our textiles...but such is no more existing

Inquiries further revealed that threads in the weaving industry are equally either imported or produced by metropolitan industries. Also, it was gathered that the thread used in the industry now comes not only in various colours and textures but also in different fibres. The view of an interviewee, a master weaver, is that:

Today, the bulk of our yarns are machine spun. Apart from replacing hand spun yarns, weavers have been much attracted to a variety of synthetic fibres including shining yarns of the silk type (siliki) and this has brought a 'great change' to the general appearance of aso-oke.

Participants at the FGD session also generally were of 
the opinion that:

The thread now in use in weaving are mostly silk, nylon and 'shine shine' (sheen materials) and a little of real cotton.

Investigations into the choice of input materials now available sustained the submission earlier made elsewhere in this paper. Importation of various yarns and the 'value' attached to them have changed, determine the taste of consumers and greatly reduced indigenous production methods of threads as synthetic fiber dominate the industry.

\subsection{Production Organization in the aso-oke Industry}

Inferences drawn from the conclusions of scholars like Lamb and Lamb (1973), Ojo (1966) and Dodwell (1955) on the problematique that the principal actors in the industry were farmers, spinners, dyers, join-men, master weavers and entrepreneurs were also validated in this study. This was expressly summarized by a participant in one of our FGD sessions:

In those days we have large production of cotton from our farmers and our women and young children process it into thread for dyers. All these are sold at the markets. Join-man (agbahun) also existed but the master weaver (bale) control weaving activities in the compound.

As gathered from the FGDs when asked on the production organization in the present industry, it was generally agreed upon that the introduction of cheap imported yarn, the change to cash crop economy like cocoa and coffee in the region and the allied socioeconomic factors affected both the production organization and productive groups in the industry. According to one participant:

The farmers, spinners and dyers are not really there now. We now depend on imported yarn from metropolitan industries and imported thread from abroad

A need exists to explore some implication of the above observation. It appears that the changes in the contemporary aso-oke industry did not only modify the roles of major classes of persons involved in the traditional industry but also the relationship that existed between weavers and marketers on the one hand and dyers, spinners, growers of cotton on the other hand as a single entity. The latter classes of people are almost severed from the production process due to the prevailing socioeconomic changes. The input of the changes can be appreciated with reference to the letter of the secretary, Western Province to the Senior Resident Office, Oyo Province which quoted inter alia:

In my opinion, our policy should be to introduce the new method of spinning and weaving (after success at controlling cotton production)... at the beginning at least, the least possible interference with the existing methods of production and marketing which have grown over the years to suit the social and economic life of the (newly created) people (Oyo Prof. 11757 Vol II)

Directly related to the transformations being experienced in the industry is the ease and cost of acquiring threads especially those synthetic ones. The sheen thread was considered by discussants equally not to be an easy teak. The problems faced in acquiring these 'metalised plastic threads' which has informed the major taste of consumers of aso-oke are considered daunting by stakeholders. Interviewees were of the opinion that apart from the rising and fluctuating cost of obtaining threads used in weaving, such scarcities often stymie their productions. Like the other aspect of the textile industry in Nigeria, another problem facing the aso-oke industry as expressed by respondents is the level of patronage. This problem was predicated upon the indiscriminate importation of textile product especially 'damask' which is in vogue in the nation. This level of importation as gathered has lowered the level of patronage of aso-oke and has further revealed such problems to be perennial. Generally, interviewees expressed their feelings on the issue as follow:

Importation of clothes not only affected the level of patronage of this business but also has lowered the profitability, thus forcing many people (weavers) to abandon weaving....as of many people (weavers) are not getting any job

The challenges facing the aso-oke industry are not new in their entirety (Renne, 1997) and most importantly a reflection of the overall challenges facing the nation's textile industry and other industries for that matter. It may be insightful to note therefore that aso-oke will surely survive the problems as always since it embodies beyond that which is seen to represent sociocultural and historical heritage and existence of a people with peculiar tradition that have seen greater adversities with proven records of triumph.

\subsection{The Potential and Perception of Developing the Textile Industry}

This study measured the potentials of the aso-oke industry from the people's perspective. This approach was particularly adopted because of the new paradigm shift in efficacious development efforts delivery as it has been proved that the best analysis of a (and approach to a ) sustainable development challenge is best given by the groups directly affected as they are the experts in the issues that most affected them (Warrington, 2008: 19). The major perception of developing the industry as largely expressed by the majority of the respondents during the FGD session hinged on the encouragement of cotton production by the government. In the words of a farmer:

In the past we had large cotton enough even for export...the land is still there for us to grow cotton for textile consumption and even for export

They were of the views that if adequate attention is given to cotton production, thread making and dye making there will be generation of employment for all and sundry. They further expressed that hand spun thread and dyed ones indeed were cheaper to acquire when cotton was grown in the southwestern Nigeria in large quantity.

Expressing further concern on how to develop the industry to full capacity and to meet contemporary market challenges, a dyer opined that there could be a mix of materials that 
could be generated from the immediate environment and the imported ones. He expanded his opinion on those from the local environment as follows:

during the colonial time, we were able to prepare khaki colour dye to provide uniform for court messengers and the ingredients are as follows...egbo idi, (root of idi tree), egbo ayin (root of ayin tree), ewe egun, ehin ire lasangba, locus bean tree, idaro (bits which fell when heated and hammered by blacksmiths. Yanko (palm kernel oil).

The range of products in the industry and the innovation observed and evident in the aso-oke industry bear witness to the potentials of satisfying local demands and export markets. One is bound to be amazed at the level of sophistication in terms of contemporary designs while still retaining its original postures. This reflects the potentials of environmental conditioning and ecological dependence of the textile industry. Thus, with the necessary technology transfer, if well annexed the idea of sustainable development and the vision of Nigeria been among the top 20 economy by the year 2020 (vision 2020 of the Federal Government of Nigeria) may be truly achievable.

\section{Conclusions}

In a scientific discourse, civilization is synonymous with culture; because the latter is the sum total efforts and achievements made by human beings to transform nature in order to make it better serving the need of the particular society in question (Darah, 1994). This perception recognizes indigenous knowledge, innovation from within, local needs, technology and ways as a system of organism which is dynamic and ever-changing. Development, beterstill, popularly acceptable quality of lives and environmental influence, are people focused and the law of social and natural justice presupposes that indigenous people are to be considered in relation to their needs, level of organization and existence in history before changes, science and technological inclusive, are engineered. When such changes appear to be unavoidable due to local and global exigencies in a compellingly globalised world, local (national) governments must prioritize local dynamics as they are the determining variables upon which all efforts draw relevance. In the case of Aso-oke, as the landscape of the industry and the society at large altered, it undoubtedly did not appear as negatively far-reaching as it turned out to be. In fact, given the high level of authority traditional rulers had in the primordial Yoruba kingdoms, traditional rulers, who were often ignorant of the ulterior motive, were heavily relied on, through the Indirect Rule system, for effective colonial cotton and industry manipulation policies.

The production of Aso-oke in traditional Yoruba society was/is effected through simple indigenous technology which was interdependent (among the other actors in the industry by forming a complex whole) and as well independent and developing at its own pace. International (global) exigencies, in the form of colonial incursions and interests in cotton, which is the principal raw material in the industry, the introduction of imported yarn and loom, in the name of making it up to date and standard is largely accountable for the present state of the industry, and more. Hence, in the global powerhouse, there are 'drivers' and 'passengers'. It is better, therefore, for governments whose citizens would be directly affected by policies to also take the drivers' seat as their local population will bear the brunt of whatever consequences as it was/is the case in that of Structural Adjustment Programme (SAP) of the 1980s. As maintained $a b$ initio, it is not the position of this paper to sentimentally antagonize contemporary policy drive of innovative Science and Technology (S\&T), rather, it is to proactively, pragmatically and empirically demonstrate through 'recent' (recent because the effects are still being felt) national development experience of Nigeria the need for policy makers in 'Developing' and 'Transitional' economies to pay elaborate attention to unspoken and usually unnegotiated global political economic undercurrents of emerging issues to avert unforeseen repercussions. This study therefore, emphasizes the need to pay deserved attention to local extra-scientific and technological dynamics even as innovative science and technology are being chorused in the global hegemony compounds.

This study has presented aso-oke in a compact manner in such a way that it gives an important view of its existence especially the way and manner the aso-oke responded to contemporary dynamics. The evidence presented her suggest that aso-oke is relatively simple in production and can be best categorized as small and medium scale enterprises as it require minimal capital and technology to produce and can consequently engage even the poor majority even with relatively simple skills. Although the industry has witnessed and still witnessing transformations, it is still subsisting. Possible explanation could be found in the responses from the field as it is easy to operate, still in ue and has sociocultural embeddednes. As already shown in the process of analysis, wearing an aso-oke is more than wearing just a cloth but conveys class, status, religion, position, tradition, history, origin, and a people amongst others too numerous to mention.

Understandably as already demonstrated, global political economy is affecting aso-oke in a new dimension, it however hold sway as it produces a new form and exist in the emerging definition of textile and fashion. As it subsists even in the face of contemporary challenges however, governme nts, international organizations, Non-Governmental Organisations (NGOs) and other stakeholders must intervene to moderate and appropriate the changes and sustenance being experienced by addressing specific issues affecting the industry, as already raised in this study, due to its material and symbolic necessity. As the world races towards the achievement of the Millennium Development Goals (MDGs), even though global political economy suggests optimism ( developments,2008), poverty is still a reality in Nigeria and does not show any sign of abating as it stands above 70 percent (National Bureau of Statistics, 2006; Federal 
Ministry of Women Affairs and Social Development, 2007), unemployment is increasing ( 11.9 percent at present [ National Bureau of Statistics, 2006]) while the aged, for example, who are the masters in traditional industry operations are being challenged by social change amongst other critical issues too numerous to mention.

The process of making aso-oke is relatively simple and labour intensive especially when compared with some of the contemporary industries. The starting capital and the operational techniques are equally simple and easy to acquire. As such, employment generation for the youth and even the elderly could be possible through aso-oke and consequently reduce rural-urban migration, poverty and, particularly, poverty among the elderly who can not cope with modern complex production process in the face of; reduced energy, insufficient economically viable children, disintegrating extended family networks and lack of social welfare to cater for them. Beyond poverty eradication among the elderly, it could also be a way of enabling them contribute meaningfully to the development of the nation. At present, elders are mostly seen as grannies/"story tellers" and often only expected to narrate tales to the young ones without direct annexation of the developmental potentials. The elders could be engaged to train school children in the art and science of aso-oke to further protect and annex the future relevance of aso-oke. This could be a way of protecting indigenous technology often used in the making of the artifact therefore leading to the protection and development of local technology rather than technology transfer.

As shown in this study, aso-oke is mostly located within the family system and perpetuated usually through informal education as the young ones are taught the art and science by the old. If the old are rendered irrelevant as they are forced out of business by the prevailing socioeconomic conditions, the transfer of knowledge necessary for the sustenance of the industry automatically becomes impossible and this is bound to be counter productive for an element of culture like aso-oke. Cases abound of cultural elements that have nearly been forced into extinction as they currently exists at the merging and often treated with disdain due to factors identical to those militating against aso-oke. Traditional divinity (the practitioner/priest is known as babalawo) and traditional herbal treatments (the practitioner is known as onisegun) are not popular and well accepted today especially among the youths and the elites and this precarious existence is traceable to the advent of Christianity especially Pentecostalism, and Islam, with the proliferation of alasalatus (socio-religious sects in Islam comparable to denominations) which portrays the babalawos and the oniseguns as 'evil' even when their services appear needed in solving some contemporary problems. They (babalawos and diviners) are considered archaic, superstitious and irrelevant in the scheme of things as most are neglected in the rural areas only to be consulted when issues reached critical levels by the hypocritical urban dwellers.

The attendant generational gaps created led to a situation whereby the knowledge and skill of divination and traditional herbal treatments were not replicated as most of the old practitioners who were experts in the 'trade' died with their skills especially as most operated through oral and spiritual therapy and training with very little written in their accounts. The few written documents could not even operate efficiently without the unwritten knowledge which was left as such due to operational secrecy. Experiences and cursory observations have shown that lot of contemporary onisegun and the babalawo especially the young ones are largely adulterated and merely exist for economic survival as their therapies have been found to be very expensive and largely ineffective as they lack sufficient requisite training even in the face of challenging health problems. The overall textile industry in Nigeria is currently in crises. Average Capacity Utilization Rates has fallen from 79.7 percent in 1976 to all time low of 48.0 percent in 2005 (Central Bank of Nigeria, 2005). Factors of ten adduced for this abysmal situation include; smuggling of imported textiles especially the popular second hand (tokunbo) clothes, lack of operating capital and high interest rates, poor infrastructure( especially power supply), and government insensitiveness amongst others identical to those facing aso-oke.

In addressing this problem, the Federal Government of Nigeria has approved various measures that directly targets specific issues. The latest of such policies is the approval N70 billion naira (US\$59.8 million) loan to textile firms in the country (The Guardian, January $15^{\text {th }}, 2008$ ) to boost confidence in the industry and enhance operating capital (a major constraint to optimal efficiency according to the policy framework).Of significance however is that criticisms and suspicion are already trailing the policies as they not yielding desired results while corruption charges are affecting the disbursement of the textile loan. It can therefore be adduced that the intervention of government may not yield the desired results if the necessary disaggregated analysis of the industry is not attempted as the industry is only nearly an octopus needing eagle eye, disaggregated and compact investigation for effective intervention efforts. Aso-oke therefore presents a case study, in a way, for the stakeholders and if the issues raised in this study are well explored, it may illuminate the path out of the present quagmire in the textile industry and better appreciation of the aso-oke. This is a major policy implication of this research article.

\section{REFERENCES}

[1] Afigbo, A.E and Okeke, C.S.1985. Weaving tradition in Igboland: History and Mechanisms of Igbo textile Industry. Nigerian Magazine. Lagos.

[2] Asakitikpi,A.O. 2007. Functions of handwoven textiles among Yoruba. Nordic Journal of African Studies. 16 (1).pp.101-115.

[3] Bascom, W.1969. The Yoruba of southwestern Nigeria. New 
York:Holt,Rinehart and Winston.

[4] Bray,J.1968.The organization of traditional weaving in Iseyin, Nigeria. Africa. 35(3).pp.271-280.

[5] Central Bank of Nigeria (CBN). 2005. Statistical Bullettin.Abuja:CBN. Vol.16.

[6] Clarke, J.1938. Ilorin Weaving. Nigeria Magazine. 14. pp.119-121.

[7] Clarke, W.H.1972. Travels and explorations in Yorubaland (1854-1858). Ibadan University Press.

[8] Developments, 2008. the run-up to 2015: can we still achieve the Millennium Development Goals? Issue 40. UK: DFID.

[9] Dodwell, C.B.1955. Iseyin: The town of weavers. Nigerian Magazine. Lagos.46.pp.118-145.

[10] Eicher, J.B.1976. Nigerian handcraft textiles.Ile-Ife: University of Ife press.

[11] Ellis, A.B.1890.The Yoruba speaking peoples of the slave coast of West Africa. London.

[12] Fadipe, C.J.1964. Indegenous skill weaving in Nigeria. Nigeria Magazine.81.

[13] Fadipe, N.A.1970. The Sociology of the Yoruba. Ibadan:Ibadan University Press.

[14] Federal Ministry of Women Affairs and Social Development (FMWA\&SD), 2007. The National Gender Policy. Nigeria: FMWA\&SD

[15] Gilroy, P.S.1987. Patterns of life: West African strips weaving. Ibadan.

[16] Lamb, V. and Holmes, J.1980.Nigeria weaving. Herting forbidity.Roxford Museum National History.

[17] Lamb, V. and Lamb, A.1973.West African strips weaving. Halifax: Halifax museum.

[18] Murray, K.1936. Women's weaving among theYoruba of Omu-Aran in Ilorin province. Nigerian Field. 5(4).pp.182-183.

[19] National Archive Ibadan Records: Oyo prof/1, 1757. Vol.II.

[20] National Bureau of Statistics (NBS). 2006 The Nigerian Statistical Fact Sheets on Economic \& Social Development. Nigeria: Federal Government of Nigeria.

[21] Ojo, E.B.2007.Printing contemporary handwoven fabrics(aso-oke) in southwestern Nigeria. DesignIssues. 23(2).pp.31-39.

[22] Ojo, G.J.A.1966. Yoruba Culture. London: University press.

[23] Olutayo, A.O.1991.The development of underdevelopment: Rural economy of Southwestern Nigeria. $\mathrm{PhD}$ Thesis (Unpublished).

[24] Olutayo, A.O. and Omobowale, O.O.2007. Production, Processing and Marketing of Export Crops for Rural Development: The Case of Cocoa in Nigeria, in Wohmuth, K, Eboue, Chicot, Gutowski, A, Jerome,A, Knedlik, T, Meyn, M and Mama, T. Africa-Commodity Dependence, Resource, Curse and Export Diversification. African Development Perspective yearbook.XII.pp.295-316.

[25] Poynor, R.1980. Trading textiles in Owo, Nigeria. African arts. 14(1).pp.47-51.

[26] Renne, E.P.1997 "Traditional Modernity" and the Economics of Handwoven cloth production in southwestern Nigeria. Economic Development and Cultural Change. 45(4).pp.773-792.

[27] Southern, E.1946. Textile Development. Progress Report, August 1946.National Archive,

[28] The Guardian, January 15th, 2008. Textile firms query 240 applicants for $70 \mathrm{~b}$ loan.

[29] Warrington, S.2008. listen carefully. Developments. the run-up to 2015: can we still achieve the Millennium Development Goals? Issue 40.pp.19 UK: DFID.

[30] Wilkes, R.S. 1946. Textile Development. DCI/1140.Oyo Prof .Letter to August Resident 